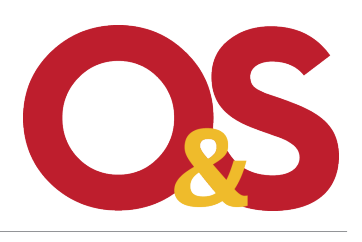

Revista Organizações \& Sociedade

2020, 27(92), 53-69

\section{Semiótica e os microfundamentos da lógica de decisão individual}

Semiotics and the Microfoundations of the Individual Decision-Making Logic (c) Autor(es) 2020

DOI 10.1590/1984-9270923

ISSN 1984-9230

www.revistaoes.ufba.br NPGA, Escola de Administração Universidade Federal da Bahia

Recebido:04 /09/2017 Aprovado: 16/08/2018

\author{
Luís Otávio Bau Macedoa \\ Maria Sylvia Macchione Saes ${ }^{b}$ \\ anniversidade Federal de Mato Grosso, Cuiabá, MT, Brasil \\ UUniversidade de São Paulo, São Paulo, SP, Brasil
}

\title{
Resumo
}

A abordagem desenvolvida visa contribuir aos estudos organizacionais proporcionando uma prescrição analítica adequada das propriedades microfundacionais dos framings comportamentais nas organizações. A concepção semiótica de Charler S. Peirce oferece meios para se combinar a gestação de representações individuais e as propriedades sociais emergentes, a partir da interação entre as instituições o ambiente competitivo e os modos de governança. A partir da abordagem semiótica, é proposto um modelo analítico dedutivo do processo de lógica de decisão individual nas organizações, identificando as contribuições de três dimensões fenomenológicas distintas: signos (instituições), objetos (ambiente competitivo) e interpretantes (estruturas de governança). Mediante a aplicação da abordagem semiótica, verifica-se o caráter holístico da interação destes três aspectos constitutivos para a emergência as representações individuais que determinam a lógica de decisão no ambiente corporativo.

Palavras-chave: Semiótica; Microfundamentos; Lógica de decisão.

\begin{abstract}
The framework developed aims to contribute to organizational studies by providing a well-developed analytical prescription for the micro-foundational properties of the behavioural framings in organizations. Charles S. Peirce's semiotic conception elaborated in his General Theory of Representations renders insights for combining the fabrics of individual representations and the emergent social properties, based on the interaction between institutions, and the competitive environment, and the modes of governance. Supported by the semiotic approach, a deductive analytical model of the individual decision-making logic in organizations is proposed, identifying the contribution of three distinctive phenomenological dimensions: signs (institutions), objects (competitive environment) and interpretants (governance structures). Employing the semiotic approach it is possible to observe the holistic nature of the interaction of these three constitutive aspects for the emergence of individuals' representations that are key to the decision-making logics in the corporative environment.
\end{abstract}

Keywords: Semiotics; Micro-foundations; Decision-Making logics. 


\section{Introdução}

O campo de investigação dos estudos organizacionais destaca-se pela abrangência de seu escopo teórico que congrega transversalmente diversas disciplinas do conhecimento humano. Em contrapartida à sua diversidade, um aspecto constitutivo que permeia as vertentes epistemológicas que buscam elucidar os fatores da emergência da firma capitalista, refere-se às concepções sobre a motivação da tomada de decisão dos agentes. Nessa perspectiva, o desenvolvimento de modelos organizacionais requer que se estabeleçam fundações analíticas a respeito das operações cognitivas dos agentes e de suas relações com a emergência dos aspectos institucionais, ético-morais e culturais da sociedade (McCloskey, 2016) ${ }^{1}$. Sob um ponto de vista evolucionário, a emergência da consciência humana não é simplesmente casual. Existe, em certa medida, uma lógica aberta, contingente e criativa que direciona a espontaneidade da realidade por mapas processuais que retratam o contexto passado e orientam as tendências futuras (Phipps, 2014). Dessa forma, ao longo do transcurso evolucionário a complexidade intensifica-se, ou seja, os graus de iniciativa, consciência e liberdade se expandem.

Convergentemente, verifica-se ao longo da última década a intensificação da busca pelo desenvolvimento dos microfundamentos teóricos para a estratégia organizacional que vão além da lógica da teoria econômica de escolha. 0 propósito precípuo desse movimento é o de modelar a influência de fatores ambientais e históricos e de suas relações com os aspectos constitutivos imanentes às organizações (Foss, 2016). Neste sentido, essa linha de pesquisa possui escopo voltado às variáveis que condicionam a estratégia corporativa a partir do individualismo metodológico, incorporando assim, os fatores ambientais e sociais. Vislumbra-se, portanto, a importância do empreendimento de esforços analíticos com vista da identificação dos aspectos constitutivos da interação coletiva no meio organizacional. Mais precisamente, refere-se à identificação dos fundamentos ontológicos do sistema econômico, entendido como uma entidade de cunho relacional, erigida a partir de arcabouços normativos (Lawson, 2003).

Por essa perspectiva, respalda-se a concepção da firma como uma entidade social que apresenta aspectos em consonância com as posições do realismo crítico. Como entidades sociais, as firmas são entes emergentes de uma estrutura normativa que define as funções, direitos e deveres que são exercidos pelos agentes que as compõem. As relações organizacionais, dessa maneira, são estruturadas e produto do caráter sincrônico da mente humana (Chassagnon, 2014). Dessa forma, evidencia-se que um aspecto central à decisão organizacional é relacionado à forma pela qual se explica a consecução de escolhas através da cognição humana. Mais relevante ao propósito presente, nessa abordagem identifica-se que o comportamento individual é resultante da operação de símbolos que atuam mediante a gestação de representações (Santaella, 2002; 2004).

Em consonância com esse recorte analítico, vislumbra-se a relevância da contribuição do filósofo pragmatista Charles Sanders Peirce (1839-1914) a partir de sua Teoria Geral das Representações. A obra de Peirce, pioneiro do pragmatismo, incorporou aspectos da teoria da probabilidade, lógica simbólica, filosofia da ciência, matemática e semiótica, em um arcabouço metafísico que objetivou a investigação das características constitutivas da mente humana. Sob o ponto de vista dos estudos organizacionais, a contribuição de Peirce emana de seu construto filosófico que descreve a operação dos signos. Retrata-se o processo semiótico através da influência concomitante das dimensões internas da subjetividade (primeiridade) e das forças ambientais (segundidade), mediadas por entidades representacionais, os signos (Colapietro, 2015; Ibri, 2015). Em certa medida, essa abordagem contorna visões dualistas da relação existente entre a mente e a matéria, pois ambas são entendidas de forma holística, percebidas como aspectos combinados da realidade. Apreende-se, complementarmente, a transitividade entre os processos coletivos e individuais sobre a constituição da agência humana, entendida como oriunda da operação semiótica.

1. Na abordagem de Douglas North (1990) os aspectos ético-morais e culturais são relacionados com a constituição de instituições de cunho informal. Na perspectiva de McClosley (2016), o conceito de instituição se circunscreve ao escopo normativo que restringe o comportamento humano (regras e normas). Nessa visão, o surgimento de novos padrões éticos e morais precede o desenvolvimento institucional, vide a o relato do processo histórico do "great enrichment" britânico. 
Em vista dos argumentos arrolados, o presente manuscrito tem o propósito de contribuir com a agenda de pesquisa das microfundamentações organizacionais, através de um olhar semiótico, do processo de decisão em âmbito individual. Complementarmente, à proposta analítica, desenvolve-se um modelo teórico que busca relacionar as contribuições dos signos para a concepção motivacional na tomada de decisão dos agentes. As contribuições da semiótica à discussão do caráter normativo da firma, sob uma perspectiva institucional, fundamentam-se a partir de três recortes: (i) a concepção semiótica da mente humana e de suas propriedades; (ii) a emergência do processo decisório individual em um ambiente coletivo; e (iii) o caráter das representações para a gestação e operação de concepções coletivas de comportamento, no âmbito organizacional. A seguir são apresentados os microfundamentos da lógica de decisão na perspectiva semiótica, a partir do qual se constrói um modelo integrativo, que fornece o entendimento das bases das motivações na tomada de decisão dos indivíduos na organização.

\title{
Concepção ontológica da organização como uma entidade social e a perspectiva semiótica de Charles Sanders Peirce
}

\author{
A organização definida como uma entidade social e de estrato ontológico
}

A perspectiva da ontologia social considera que as estruturas sociais e suas propriedades possuem aspectos constitutivos próprios e reais que as distinguem das demais entidades contingentes da existência material, tais como os seres vivos e os objetos inanimados. Conforme Searle (2005) aponta, a realidade dos fenômenos sociais não se coaduna com uma posição favorável ao idealismo filosófico, pois em última medida as estruturas sociais sofrem influência dos denominados "basic facts", ou seja, as leis que atuam sobre a realidade material. Como campo de investigação científico específico são passíveis de objetividade epistemológica e rigor científico, contudo, interconectado com as leis que regem as forças fundamentais da natureza². De acordo com essa visão, sob o olhar das teorias organizacionais, evidencia-se que a discussão da natureza da firma, usualmente empreendida, realiza-se sob uma perspectiva puramente epistemológica. Ao se adotar uma postura investigativa que não enfatiza o caráter ontológico das organizações, busca-se responder os determinantes de sua emergência e a avaliação de suas funções, mas não se descreve as suas características constitutivas. Neste sentido, se destacam formulações teóricas que a remetem como uma entidade que objetiva, por exemplo, a minimização de (i) custos de produção, de (ii) custos de transação e mensuração e que (iii) congrega recursos idiossincráticos que gestam a emergência de vantagens competitivas. Vislumbra-se, desse modo, que as diversas perspectivas teóricas do campo organizacional têm o propósito de elucidar a "causa" subjacente da existência da organização capitalista, sem compreender a sua concepção como uma entidade emergente, ontologicamente definida, e de existência real.

Mormente, as divergências entre as abordagens organizacionais referem-se à delimitação epistemológica do comportamento dos agentes, tais como suas características cognitivas e de processamento de informações que delimitam a atuação e função da firma capitalista. A abordagem neoclássica, ao definir como premissa a plena racionalidade dos indivíduos, tende, portanto, a considerar irrelevantes os processos organizacionais de tomada de decisão. As organizações, então, são representadas como uma função de produção que congrega fatores, com vistas da maximização do lucro. Por outro lado, ao se introduzir a premissa de racionalidade limitada e incerteza, na linha de Coase (1936), evidencia-se a emergência de custos de transação. A organização passa a ser uma estrutura de governança das relações dos agentes que a constituem com vistas da minimização de custos de transação vis-à-vis os custos organizacionais. Adicionalmente, o entendimento da organização como um "feixe" de recursos evidencia a perspectiva desta como um lócus de gestação de recursos que possibilita a geração de vantagens competitivas e, dessa forma, a captura de valor (Barney, 1991).

2. Refere-se às quatro forças interativas fundamentais da natureza: gravitacional, eletromagnética, interação fraca e interação forte. 
Segundo Lawson (2015), apesar das contribuições que essas perspectivas fornecem, elas não permitem o entendimento da natureza constitutiva das organizações, no sentido de seu caráter coletivo composto por estruturas relacionais. Em certo sentido, ao se delimitar a natureza de uma entidade social a partir de premissas epistemológicas, corre-se o risco de defini-la ontologicamente como uma entidade abstrata que não possui existência real. Encaixam-se nesse enquadramento, por exemplo, as definições como uma função de produção, um nexo de contratos ou um feixe de recursos. Ou seja, fica evidente a caracterização abstrata dessas abordagens epistemológicas, pelas quais não se formalizam o conjunto de atributos ontológicos que constituem a sua interação com o sistema social. Por outro lado, ao se prescindir a análise de seu caráter ontológico, a organização pode ser representada e definida no modo de um indivíduo, sobretudo delimitada por seu caráter jurídico próprio, omitindo-se o seu escopo constitutivo coletivo. Nesse sentido, não se incorpora à análise a sua estrutura relacional interna, caracterizada pela justaposição de direitos e obrigações que delimitam a interação social sob a sua jurisdição (Chassagnon, 2014).

Percebe-se, portanto, a partir dessa exposição, a importância da observância dos atributos ontológicos das organizações como entidades sociais. A partir de uma perspectiva constitutiva e relacional é caracterizada por processos de posicionamento e estrutura, aos quais são sobrepostos obrigações e direitos (Lawson, 2015). A atribuição normativa é posicional, ou seja, não é relativa a indivíduos, mas sim, às posições exercidas pelos indivíduos. As estruturas sociais, assim, são constituídas pelo conjunto de posições sociais e, consequentemente, regidas pelos direitos e obrigações alocados a cada posição (Lawson, 1996). As organizações possuem a capacidade de estabelecerem "poderes" que são usufruídos pelos indivíduos que as compõem a partir do exercício de direitos e obrigações correspondentes às suas posições sociais. Por exemplo, através da governança corporativa são desenvolvidos sistemas normativos que atuam de forma a garantir a padronização de práticas comportamentais, em consonância com as estratégias organizacionais e o marco legal vigente.

Um aspecto central da conceituação ontológica das estruturas sociais é relacionado à discussão quanto à redutibilidade de suas propriedades constitutivas em relação aos entes que as compõem. Neste sentido, a perspectiva de Lawson (2012), pressupõe a irredutibilidade ontológica das estruturas sociais. Ou seja, considera que as propriedades ontológicas das estruturas sociais são sincronicamente e distintamente derivadas das entidades que as constituem (e.g. indivíduos). Nesta perspectiva, as estruturas sociais são oriundas de um escopo ontológico próprio, determinado pelo caráter organizativo das relações humanas, composto pela estruturação de práticas e crenças. Searle (1984), adicionalmente, defende que o caráter ontológico central das estruturas sociais é dessas serem direcionadas diretamente pela intencionalidade humana ${ }^{3}$ consubstanciada na intencionalidade coletiva. As propriedades emergentes das estruturas sociais são redutíveis aos seus componentes constituintes. Fica evidente que essa posição se coaduna com uma visão favorável ao individualismo metodológico.

Adicionalmente, esse entendimento aponta que as Ciências Sociais "at their best are theories of pure and applied intentionality" (Searle, 1984, p.81), assim sendo, são direcionadas e resultantes da intencionalidade humana. Nesse ponto é que Lawson $(1996 ; 2012)$, Searle $(1984 ; 2005)$ defendem que as estruturas sociais possuem um caráter ontológico próprio, não reduzível às leis da realidade natural.

Um ponto crucial desse entendimento é o de que as estruturas organizacionais requerem, para sua constituição, do caráter reflexivo dos indivíduos que as compõem. Em certa medida, as entidades sociais, como as organizações, são resultado da gestação de atitudes mentais individuais que se consubstanciam na emergência de percepções cognitivas coletivas. Essa definição, denominada por Tuomela (2003) por "we attitutes", é composta por crenças e intenções comungadas pelo grupo social. Primordial para essa perspectiva de sociabilidade refere-se à aceitação, por parte dos indivíduos, das estruturas normativas que constituem a interação coletiva. A aceitação se refere à conformidade da percepção cognitiva individual das normas sociais,

3. Intencionalidade no sentido de Searle (2005) refere-se ao fato de serem direcionadas a partir da consciência humana, através de emanações mentais, tais como as emoções, desejos e medo, entre outros. 
ou seja, "action is based on the idea of doing something at will under the guidance of beliefs" (Tuomela, 2003 , p. 125). Isso, todavia, não significa que as estruturas sociais, para serem operacionais, necessitam da concordância quanto ao seu conteúdo normativo, mas sim que os participantes do grupo devam acordar quanto a sua legitimidade ${ }^{4}$.

Como consequência da relação existente entre a emergência das estruturas sociais e o processo de gestação de significados pela consciência humana, evidencia-se que as instituições possuem caráter simbólico. A realidade social, de acordo com a ontologia social, pode ser descrita como o produto de conjuntos de signos que sinalizam e descrevem padrões comportamentais que são aceitos coletivamente (Nellhaus, 1998). A atribuição dos signos sociais é de atuarem como regras e convenções que possuem função normativa e, portanto, institucional (Santaella, 2002). As estruturas sociais são resultado da emergência de processos cognitivos gestados através da mente humana a partir da operação de símbolos representacionais. 0 próprio desenvolvimento da cognição humana é consequência da operação de signos, tais como a linguagem e a escrita, ou mesmo a matemática, ou seja, é resultado de mecanismos semióticos (Searle, 2005). A produção de representações se constitui em instrumento cognitivo para a emergência da realidade social. Em síntese, ao se incorporar a semiótica ao estudo da realidade social, identifica-se a relevância de se aprofundar a concepção da gestação de representações. Nesse ponto, destacam-se as contribuições para a semiótica do filósofo pragmatista Charles Sanders Peirce (1839-1914), reflexões essas centradas em suas categorias fenomenológicas que serão discutidas na próxima seção.

\section{A teoria geral das representações de Peirce e o papel dos signos no contexto das estruturas sociais}

O pragmatismo de Peirce é resultante de sua crítica ao cartesianismo filosófico estabelecido a partir do dualismo entre a mente humana e a realidade contingente. Amplamente difundido, o "cogito" de Descartes funda-se na lógica de que o conhecimento é precedente à experiência empírica e que se requer ceticismo e distanciamento entre o ente investigativo e o objeto de análise (Bacon, 2012). A objeção de Peirce a esse posicionamento filosófico, parte da percepção de que as concepções elaboradas pela mente humana são produtos da associação de ideias e impressões sensoriais oriundas do ambiente externo. Ou seja, o princípio do dualismo é reducionista. Em certa medida, o propósito de Peirce foi o de fundar o empirismo epistemológico sobre novas bases (Ibri, 2015). O autor postula a influência decisiva do contexto de experiências ao conhecimento humano, nas suas palavras, "our whole knowledge of the internal world is derived from the observation of the external world" (CP 5.244)5.

Ressalta-se, assim, que a operacionalização da mente humana se dá através da contínua interação entre os estados cognitivos internos e os sinais sensoriais externos. Adicionalmente, a sua concepção de mente inclui não somente humanos, pois incorpora o mundo animal e a realidade não sensorial ${ }^{6}$. A concepção sui generis de mente de Peirce é, portanto, determinada pela produção de signos que exercem função informacional, dessa maneira, é fundada sobre uma perspectiva semiótica. Nesse sentido, a sua tríade semiótica é composta por objetos, signos e interpretantes. Os signos são instrumentos ideacionais que representam os objetos, enquanto os interpretantes são os significados produzidos a partir da relação entre os signos e os objetos. Pode-se

4. Essa perspectiva aponta que mesmo o poder coercitivo do Estado e as estruturas de poder das estruturas sociais são sincronicamente emergentes das interações relacionais, ou seja, são oriundas da ação coletiva orientada pela intencionalidade dos grupos sociais.

5. Todas as referências dos escritos de Peirce são relacionadas aos Collected Papers, citados mediante a abreviação CP seguida pelo número do volume e parágrafo.

6. Nesse aspecto, a cosmologia de Peirce é desenvolvida sobre um processo evolucionário universalista que se inicia pela constituição a partir da aleatoriedade fundamental da realidade até a emergência de hábitos que dão origem a leis naturais. Dessa forma, em certo sentido Peirce, considera que o processo semiótico é operacionalizado mesmo pelo mundo material, não sendo uma exclusividade da cognição humana, apesar de nessa ser realizada em um plano evolucionário mais sofisticado que alcança os aspectos morais, vide, por exemplo, Colapietro (2015) e Ibri (2015). 
descrever o conceito de representante como a "tradução" do objeto gestado pela mente humana a partir da codificação de informações contidas no signo (Randsell, 1977). Um aspecto central da visão de Peirce é a de que os signos são "something which stands to somebody for something in some respect or capacity" (CP 2.228), portanto, depreende-se que possuem um caráter de intencionalidade e direção em vistas a um objetivo ou efeito 7 .

Em síntese, o processo semiótico, proposto por Peirce, congrega três instâncias representativas: (i) inferência (objeto), (ii) comunicação (signo) e (iii) sentido (interpretante). 0 processo semiótico ocorre de forma unívoca e indissociável a partir dessas três dimensões, produzindo a denominada semiosis, ou seja, a produção de representações (Colapietro, 2015). O processo semiótico é interligado à tríade de categorias fenomenológicas que respaldam a abordagem cosmológica de Peirce. Mais precisamente, através das categorias fenomenológicas, orientadas por uma metafísica de escopo universal, processam-se os modos de ser das experiências da mente humana. A primeiridade (firstness) relaciona-se com os atributos de qualidade, espontaneidade, unidade e possibilidade das experiências. Consequentemente, representa as qualidades subjetivas e idiossincráticas da mente, originadas da aleatoriedade dessa dimensão experiencial. A segundidade (secondness), por sua vez, indica as propriedades exercidas pela interação do objeto com o mundo externo. Essa força se circunscreve pelo caráter de oposição e discricionariedade em que o mundo tangível exerce seu poder de oposição (over-againstness) em relação à primeiridade. Por conseguinte, a terceiridade exerce a função de mediação e significação das categorias anteriores, assim, possibilita a constituição de leis e tendências que surgem a partir de hábitos (Rosenthal, 1990).

As categorias fenomenológicas atuam de forma unívoca, por conseguinte, não podem ser analisadas de forma dissociada. Sob a perspectiva do self humano, a primeiridade reflete a diversidade e singularidade dos sentimentos e da subjetividade que se confronta com a concretude e oposição diádicas representadas pelo ambiente externo (segundidade). Como resultado desse embate, desenvolvem-se representações ao longo do continuum evolucionário, desenvolvidas a partir da terceiridade. Toda a produção cultural, artística e intelectual oriundas da cognição humana é produto dessa categoria, apesar de não estar circunscrita a ela. Em certa medida, Peirce, segundo sua posição pragmatista, retrata a estreita complementariedade entre experiência e cognição, sendo que na sua visão, pensar nada mais é do que "... the cognitive result of living" (Ibri, 2015, p. 34).

Depreende-se, assim, que a operação da mente humana se desenvolve sob a fundação ontológica composta pelas três categorias fenomenológicas. Todavia, a absorção da ontologia de Peirce só é realizada plenamente ao se analisar dois aspectos centrais que congregam a sua visão da realidade contingente. Ressalte-se que ambos são oriundos de sua perspectiva evolucionária. O primeiro é denominado por sinequismo (synechism) e refere-se ao caráter processual e contínuo da realidade e que se coaduna com a impermanência dos estados da realidade. Através do sinequismo, Peirce desenvolve uma descrição ontológica pautada pela emergência condicionada, ou seja, em que todos os estados da realidade são contingentes de estágios evolucionários pretéritos. Essa concepção processual pode dar origem a generalizações, ou seja, a uma redução da diversidade de estados contingentes, mas isso não é uma condição inerente. Nesse ponto, tangencia-se ao entendimento do segundo aspecto constitutivo da ontologia de Peirce que é o tiquismo (tychism), ou seja, o caráter estocástico da realidade. A indeterminação dos estados existenciais condiciona um "continuum" de possibilidades sempre aberto a transformações. Desse modo, a emergência de padrões ou leis é oriunda de um "womb of indeterminacy" (CP 1.412) que, dentro de si, gesta a diversidade aleatória e o contínuo evolutivo.

7. Peirce classifica os signos, a partir de sua relação com o objeto, em três formas distintas: ícones, índices e símbolos. Os ícones mantêm uma relação de similaridade e analogia (e.g. uma figura, um modelo teórico, uma fotografia); já os índices retratam uma relação sensorial (e.g. nuvens negras com a possibilidade de chuva); por fim, os símbolos são representações que possuem uma origem a partir de convenções ou normas sociais (e.g. a palavra gato representa no idioma português uma determinada espécie animal) (Nellhaus, 1998). 
Torna-se relevante, neste ponto, relacionar as implicações da semiótica para a concepção ontológica das estruturas sociais. A proposta discutida no presente manuscrito é a de que os mecanismos semióticos da mente humana se constituem no cerne emergente da realidade social. Peirce desenvolve uma detalhada e holística descrição da operação dos processos cognitivos da mente humana através de sistemas de signos representativos. As concepções da realidade dão-se mediante a operacionalização de formulações simbólicas de cunho social. Nesse aspecto, é fundamental o entendimento de que a produção de concepções da realidade é uma prática coletiva, pois se realiza mediante instrumentos semióticos, que se dão mediante relações interpessoais. Portanto, a cognição humana é gestada em um contexto constitutivo que a determina e que estabelece os próprios meios de seu desenvolvimento (e.g. linguagem).

A contextualização descrita acima, todavia, não remete a uma posição secundária para a agência humana. Segundo Peirce (CP 6.157), a personalidade individual é formada a partir de uma perspectiva de futuro, ou seja, de intencionalidade. Adicionalmente, de acordo com sua narrativa, o autocontrole é uma propriedade fundamental que orienta as escolhas individuais. Portanto, exerce papel central o componente moral da autodeterminação. Três mecanismos operativos são cruciais para sua operacionalização pela mente humana: (i) consciência, (ii) ação, e (iii) formação de hábitos. O primeiro tem relação com a propriedade adjacente de percepção de estados mentais internos (subjetivos) e externos (objetivos) e, principalmente, de sua singularidade. 0 segundo refere-se à orientação indissociável da espécie humana com a atuação sobre a realidade contingente. 0 terceiro, por último, é a capacidade constitutiva de aquisição e abandono de propensões habituais (Brier, 2008).

Do processo semiótico, mediante a operação da terceira categoria, decorre a produção de novas representações (interpretantes), essas que, por sua vez, determinam novos modos comportamentais. Portanto, o caráter constitutivo da moralidade possui relação com as escolhas de ações e formas de pensar que se tornam habituais. Dessa forma, nesse aspecto dinâmico, reside o cerne da autodeterminação individual. Entretanto, evidencia-se que essa exposição não é dual, pois a própria semiosis incorpora em seu âmago as influências das forças indutoras externas, exercidas pela segundidade. Isso evidencia que o enfoque de Peirce não é reducionista. A consciência humana é retratada como produto do processo evolucionário que congrega as ações dos mecanismos de seleção ambiental e variação individual. Essa posição holística, integrada em um corpo teórico unificador, faz frente a posições que privilegiam narrativas duais, centradas na ênfase relegada aos papéis de entidades ambientais (macro) ou individuais (micro) para a emergência das estruturas sociais.

\section{Os microfundamentos da lógica de decisão individual numa perspectiva semiótica e organizacional}

\section{Microfundamentos e o modelo de "goal framing"}

Nas últimas décadas os estudos sobre microfundamentos têm se tornados cada vez mais presentes no campo de estratégia das organizações. Esse movimento objetiva entender como as relações entre variáveis macros são mediadas por ações e interações micro, e como estas impactam as organizações em termos de desempenho (Felin, Foss \& Plopyhart, 2015; Foss, 2016; Molina-Azorín, 2014; Helfat \& Peteraf, 2015).

De um lado, esse programa de pesquisa surge como uma crítica à lógica da teoria da escolha racional, que assume os indivíduos cognitivamente homogêneos e passíveis de simples agregação, ignorando as influências sociais e psicológicas sobre o comportamento. Essa construção abstrata da natureza do tomador de decisão impossibilita explicar a heterogeneidade das firmas (Foss, 2004; 2010; 2011). Se os empresários são racionais, possuem informação plena e a mesma compreensão da realidade, eles avaliam igualmente as oportunidades e seguem a mesma estratégia. A única fonte de vantagens competitiva seria, portanto, rendas monopolistas advindas de estruturas de mercado concentradas. Sob essa perspectiva, Porter (1985) argumenta que as firmas pertencentes a uma indústria se aglomeram em grupos estratégicos, nos quais movimentos entre tais grupos são orientados a partir de opções estratégicas implementadas mediante ações de 
gestão. $O$ fundamento, portanto, que atribui à estrutura do mercado a principal fonte de vantagens competitiva é a teoria da Organização Industrial, que traz os pressupostos da escolha racional e não vê papel da ação gerencial como mecanismo determinante de resultados. Várias pesquisas, as quais têm como precursores Schmalensee (1985), Rumelt (1991) e McGahan e Porter (1997), analisaram o poder explicativo de fatores, como - corporação, firma, indústria e ano - sobre a variabilidade de desempenho das firmas colocando no cerne da questão: a heterogeneidade das firmas. Os resultados depois replicados em outros ambientes (ver, por exemplo, Carvalho, Bandeira-de-Mello, Gonçalves, Vianna \& Marcon, 2009; Vianna \& Marcon, 2009; Goldszmidt, Brito \& Vasconcelos, 2011) mostraram que o efeito organizacional, ou seus recursos específicos, influenciam na diferenciação de desempenho.

De outro lado, a abordagem de microfundamentos também surge como crítica à teoria institucional. Embora esta teoria permita entender o fenômeno da heterogeneidade organizacional, suas construções centrais incluem conceitos macro, tais como: rotinas, capacidades, competências, interação entre recursos -, difíceis de proverem uma lógica discriminante e de serem observados ${ }^{8}$. Nesse caso, a proposta da abordagem de microfundamentos é explicar a heterogeneidade organizacional e as vantagens competitivas, por meio de variáveis fundamentais e estáveis. A lógica que está por traz dessa argumentação é a de que as ligações entre as variáveis macros são sempre mediadas pela ação individual e suas interações. Uma vez que o comportamento das organizações é resultante das ações de suas partes componentes, sustenta-se que o conhecimento dos fundamentos das ações individuais permite previsibilidade das relações, que é uma condição para apresentar prescrições. Microfundamentos são, por conseguinte, parte importante da gestão estratégica visando prescrição de políticas privadas (Abell, Felin \& Foss, 2008), assim como públicas9.

Portanto, a proposta microfundamentos argumenta a favor de se entender os elementos que condicionam as diferentes estratégias e desempenho das organizações, a partir do nível do indivíduo, dando espaço para as dimensões psicológicas da gestão estratégica. Destaque-se que, o movimento das microfundamentações incorpora um conjunto grande de argumentos e teorias (veja: Felin, Foss \& Ployhart, 2015). Para fins da análise proposta neste ensaio, será abordada o Goal-framing Mode/ concebido por Lindenberg (2001), denominado um "method of decreasing abstraction" (Heckathorn, 2005, p. 551), já que se trata de "models simple enough to remain analytically tractable while not being so unrealistic as to be trivial". Essa abordagem tem a vantagem de incorporar a concepção da racionalidade presente na teoria econômica tradicional, na qual se identifica contextos que se adaptam bem, incluindo também domínios explicativos de outras áreas de conhecimento, particularmente aplicando o insight da cognição social.

Lindenberg (2001) identifica mecanismos que levam à tomada de decisão. Um deles é a atenção seletiva e o outro são a formação e as mudanças de preferências. Estes se orientam por múltiplos objetivos que competem entre si. Por exemplo, objetivos de como auferir maior renda, desfrutar lazer, ajudar amigos, valores familiares e religiosos oferecem guias conflitantes para a ação. 0 objetivo que prevalece se move para o primeiro plano e determina a tomada de decisão, incluindo a determinação de quais aspectos são relevantes (ou seja, atenção seletiva) e quais conhecimentos devem ser acionados para isso. Como resultado, a orientação da ação é auto-interessada ou altruísta, cooperativa ou competitiva. No entanto, as metas subordinadas não

8. Grosso modo, pode-se dividir esse grupo de pesquisa em duas perspectivas. A corrente ligada à Escola Industrial de Chicago que se fundamenta pela lógica do equilíbrio competitivo (suposição de racionalidade forte) mas com firmas heterogêneas, devido à existência de barreiras informacionais. Representantes dessa escola estão Demsetz (1988), Lippman e Rumelt (1982), Wernerfelt (1984), Barney, (1986a, 1986b, 1991, 2002), Dierickx e Cool (1989) e Peteraf, (1993). De um cunho mais heterodoxo, admitindo economia em constante desequilíbrio e modelo de decisão processual, tem-se uma perspectiva associada a um conjunto de conceitos, tais como: Core Competence (Prahalad \& Hamel, 1990), Capabilities (Nelson \& Winter, 1982), Dynamics Capabilities (Teece, Pisano \& Shuen, 1997), Knowledge (Malerba \& Orsenigo, 2000), entre outros.

9. Veja por exemplo, o estudo do World Bank Group (2015). O relatório Mind, society, and behavior busca integrar recentes estudos em psicologia e fundamentos sociais do comportamento humano, entender de forma a melhorar o desenho e adoção de políticas de desenvolvimento e de combate à pobreza. Em particular o relatório argumenta que a tomada de decisão do indivíduo ocorre por meio de três princípios de pensamento: (1) automático, (2) social (identidade social), (3) modelos mentais. 
perdem totalmente o poder de influência. Este poder depende de seu peso em relação ao objetivo dominante, já que a percepção de uma pessoa sobre uma situação é seletiva e depende da sua estrutura cognitiva.

Por outra parte, Lindenberg (2001) coloca que o comportamento é primariamente influenciado pela provisão de recompensas externas ${ }^{10}$. A chave desse argumento é a distinção entre três objetivos distintos, que fazem parte das motivações humanas: 1) hedônico: o objetivo é melhorar o bem-estar diretamente e imediatamente. Essa estrutura é tida como a mais forte. Esse objetivo ativa um ou mais sub-objetivos que promove a melhora de um sentimento numa particular situação, por exemplo, evitar esforço negativo, evitar incertezas ou busca imediata de prazer; 2) de ganhos: objetivo de aumentar a riqueza/recursos no médio e longo prazos (por exemplo, investir em educação); 3) normativo: objetivo de agir de forma apropriada de acordo com as normas. A noção de "logic of appropriateness" de James March (Foss, 2004) explica o comportamento normativo, em que as pessoas agem de acordo com o que elas (e os outros) consideram apropriado, em um determinado contexto, não adotando uma lógica estritamente maximizadora. Observa-se, no entanto, que esse objetivo é mais fraco, de forma que ela irá deslocar o primeiro apenas se for suportado por estruturas sociais ou institucionais com influência.

Essa teoria pode ser aplicada em uma variedade de contextos. Foss (2011) lançando mão da Goal-framing theory aponta que no coração da motivação para a produção conjunta está o goal-frame normativo, cujo objetivo é a organização per se. A cultura organizacional pode ser vista como um exemplo de como a informação poderia levar a ações cooperativas ou pró-sociais em detrimento das outras duas motivações, evitando risco moral e comportamento oportunista. Lindenberg e Steg (2007, p. 120) aplicam a abordagem no contexto ambiental, dando também destaque para o objetivo normativo como motivador do agir maneira adequada, contribuindo para um ambiente limpo "It will make people especially sensitive to what they think one ought to do (what the other people are doing)". Portanto, os indivíduos mais conscientes dos problemas ambientais vão se envolver em atividades pró-ambiente dando menos atenção a outros objetivos, tais como incentivos monetários.

Esse modelo sugere que, em contextos organizacionais, particularmente os que dependem da produção conjunta, os tomadores de decisão necessitam promover o comportamento normativo, que são mais custosos para os agentes se engajarem. Os ambientes que favorecem a lógica de ganhos coletivos vis-à-vis individuais são aqueles que facilitam o fortalecimento de crenças com relação ao comportamento pró-coletivo. Entretanto, como destaca os autores (Foss \& Lindenberg, 2013), os gestores devem prover incentivos e controles aos indivíduos de forma a fortalecer os objetivos coletivos, mantendo, por outro lado, o empenho e a busca de ganhos com orientação individual.

\section{"Goal framing" e a semiótica da lógica de decisão individual}

Em consonância com a exposição prévia, objetiva-se descrever nesta seção uma proposta de fundamentação analítica da decisão individual em um ambiente organizacional, a partir da semiótica de Peirce. Seguindo a perspectiva das microfundamentações, o modelo de "goal framing" (Foss \& Lindenberg, 2013) estabelece as motivações humanas em termos hedônicos, de ganhos e normativos. Como resultante, o grau de eficácia da organização em alcançar objetivos sustentáveis no longo prazo é determinado pela emergência do "framing" normativo. Ou seja, a constituição de um ambiente organizacional que produza um padrão de comportamento individual, alinhado aos objetivos coletivos, é o fator determinante para a eficácia da estratégia corporativa. Convergentemente, sob a perspectiva ontológica, a organização é constituída por interações humanas estrutu-

10. Heckathorn (2005) observa que a abordagem de Lindenberg se assemelha ao conceito de preferências gerais de Gary Becker, vistas como parte da condição humana. O objetivo normativo (socialmente determinado) se traduz tanto em bem-estar físico como social, tal como um bom relacionamento com o parceiro. Devido ao objetivo socialmente determinado, a maioria das preferências é fundamentada socialmente, indicando se tratar de uma teoria da racionalidade "social" (em oposição à racionalidade "natural"). 
radas normativamente, mediante posições e funções que determinam direitos e deveres (Chassagnon, 2014). 0 aspecto central dessa orientação é o modo pelo qual os indivíduos desenvolvem concepções do ambiente organizacional, mediante o emprego de instrumentos de governança pela gestão estratégica. Conforme propõem Foss e Lindenberg (2013), a gestão organizacional deve implantar incentivos e controles que tenham a capacidade de fortalecer os objetivos coletivos, sem desmobilizar o empenho e a busca de ganhos com orientação individual. Neste sentido, diversas prescrições são fornecidas pelos autores, tais como a ênfase em objetivos organizacionais coletivos, a concessão de prêmios relacionados a metas compartilhadas pelo grupo e a gestão mediante estruturas horizontais.

A proposta do presente ensaio, todavia, identifica que em última instância a emergência das percepções individuais é resultado da concepção semiótica descrita pela contribuição de Peirce. A gestação de "framings" é resultado da produção de representações pelos indivíduos a partir da interpretação do ambiente competitivo ao qual a corporação está inserida, mediante o emprego de signos de uso coletivo. No ambiente corporativo, entende-se por signos todo o arcabouço normativo que estrutura as relações sociais, englobando instrumentos formais e informais, ou seja, as instituições. Como resultado da interação entre as duas dimensões (ambiente competitivo e instituições) desenvolvem-se padrões comportamentais que se substanciam mediante o emprego de modos de governança organizacional. Esses, por sua vez, atuam como respostas ao ambiente externo à organização de forma a se atingir a consecução de uma estratégia corporativa. Numa perspectiva semiótica, o ambiente competitivo é constituído pela dimensão fenomenológica da segundidade, caracterizado por seu exercício de força e oposição, ao qual a corporação se insere e se defronta. Em certa medida, o arcabouço de governança da firma é resultado da concomitante interação entre essa influência ambiental externa e a gestação de representações pelos indivíduos que compõem a organização (semiose). Vislumbra-se, portanto, a convergência dessa perspectiva conceitual com a gestação de "framings" normativos expostos por Lindenberg e Steg (2007) e Foss (2011).

A Figura 1 identifica os eixos centrais da proposta analítica desenvolvida, sendo que o primeiro aspecto a ser destacado é a relação entre as dimensões micro (indivíduos) e macro (social). Conforme indicam as abordagens ontológicas de Searle (2005) e Lawson (2012), os fenômenos sociais são emergentes e sincronicamente derivados dos elementos que os compõem. Nesse ponto, é que a organização pode ser entendida como resultado das propriedades constitutivas dos indivíduos. Essa relação, porém, é estruturada a partir de sistemas normativos gerais (macro) e organizacionais (micro) que restringem e moldam os comportamentos individuais, mediante o estabelecimento de funções, direitos e deveres que dão origem a hábitos e rotinas. Ou seja, a influência ambiental atua sobre os padrões comportamentais, mediante o exercício do arcabouço normativo que molda a lógica de decisão individual. Respalda-se, nessa abordagem, a posição de Hodgson (2006, 2019) e Lawson (2015) que defendem a propriedade normativa e, portanto, institucional, da organização relacionada à sua estrutura de governança. Numa perspectiva macro, as organizações possuem o caráter de entidades sociais que operam em interação com outras entidades, sendo, assim, são instrumentos de ação coletiva (Hodgson, 2007). Evidencia-se, portanto, a propriedade ontológica dual da corporação, por exemplo, em que, sob um prisma micro, constitui-se em uma estrutura social que congrega ações individuais e, numa instância macro, desempenha o papel normativo de uma entidade jurídica. Conforme retrata Lawson (2015), a corporação capitalista possui uma natureza legal constitutiva ${ }^{11}$, no sentido institucional do termo, que estabelece o conjunto de atributos, direitos e deveres que regulam a sua atuação. Por outro lado, caracteriza-se por ser um sistema organizado de interação social, regido por uma estrutura normativa e relacional. As organizações apresentam, sob uma perspectiva micro, as propriedades de uma "social community" (Lawson, 2015, p. 5), em que a aprendizagem e a aculturação desempenham papéis relevantes ao desenvolvimento de hábitos e rotinas. Consequentemente, a gestação de culturas é um processo de maturação longo que conduz à crescente homogeneização de comportamentos e idiossincrasia organizacional (Chassagnon, 2014).

11. Lawson (2015) descreve a longa evolução histórica do desenvolvimento do atual modelo legal britânico e, posteriormente adotado globalmente, de classificação da firma capitalista nos moldes de Limited Company e Corporation. 


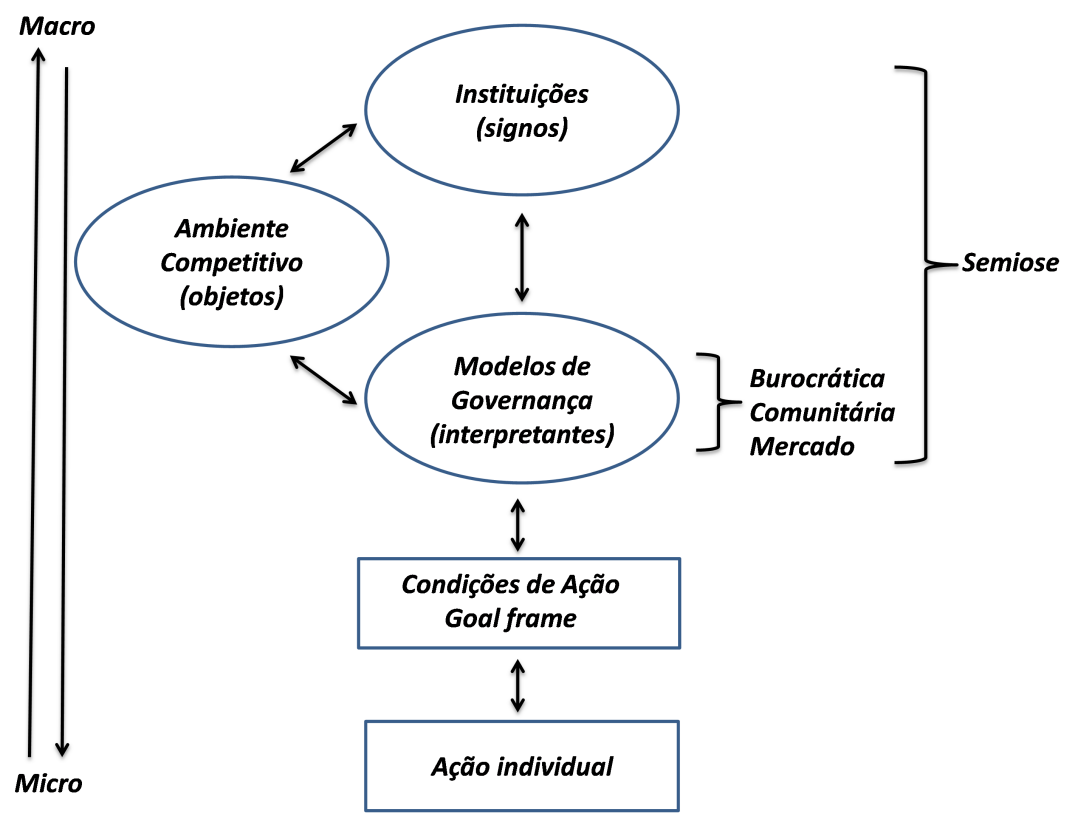

Figura 1 - Modelo semiótico organizacional de decisão individual Fonte: Elaborado pelos autores.

Em sentido inverso, a influência da autonomia individual não pode ser minimizada, pois a cultura organizacional possui um escopo mutável e processual. Essa perspectiva holística coaduna-se com o conceito de "reconstitutive downward causation", postulada por Hodgson (2007). A causação "top-down" realiza-se mediante a operação dos instrumentos normativos macro e de gestão organizacional que operam sobre as escolhas individuais. Os agentes, contudo, não são entes autômatos, pelo contrário, conforme Peirce (CP, 6.101) apontou a mente humana "has acquired in a remarkable degree a habit of taking and laying aside habits". Ou seja, os comportamentos habituais são ratificados ou não, perante o seu caráter instrumental, ou seja, em decorrência de sua adequabilidade frente à realidade tangível.

Consequentemente, a abordagem analítica proposta fundamenta-se no processo de decisão organizacional oriundo de interações individuais de cunho semiótico. Nessa direção, conforme aponta Searle (2005), as estruturas sociais são consequentes de operações simbólicas e linguísticas. Portanto, são emergentes das propriedades representacionais oriundas da interpretação de signos socialmente aceitos. A semiose (produção de representações) apresenta caráter simbólico, no qual os signos exercem a função de codificações sociais da realidade ambiental. Em sentido inverso, a influência ambiental, relacionada ao mercado, induz a gestação de estratégias organizacionais, implementadas a partir das estruturas de governança. Sob uma perspectiva da eficácia estratégica, esse mecanismo apresenta caráter contextual. A prescrição e validação empíricas de políticas voltadas à produção do "framing" normativo, na linha de Foss e Lindenberg (2001), são resultantes da interação entre a matriz normativa vigente, o ambiente competitivo e o modo de governança organizacional. Deste modo, apesar de possíveis generalizações, orientadas à adoção de incentivos que se coaduna com objetivos coletivos, a especificação de políticas apresenta certo grau idiossincrático. Esforços analíticos de modelagem com propósitos previsionais, conforme descreve Peirce (CP, 1.412), devem incorporar o prevalente caráter estocástico da realidade (tiquismo), especialmente quando relacionado à emergência de intenções compartilhadas.

Neste ponto torna-se relevante discutir a influência de dimensões ambientais (macro) e suas interações com a dinâmica organizacional de âmbito micro. Peirce, nesse aspecto, enfatiza o caráter plural da existência humana, pois as categorias fenomenológicas operam em uma escala em que a agência individual, quando 
isolada, manifesta-se apenas em "ignorance and error" (CP, 7.528). Nesse sentido, toda a estrutura social, apesar de centrada em operações semióticas de origem individual, apoia-se sobre entidades de existência coletiva. Em primeiro plano, conforme aponta Searle (2005), as estruturas sociais são emergentes da codificação simbólica (signos), tais como a linguagem, as leis, a moeda e os sistemas políticos, entre incontáveis outros. Todas essas representações constituem-se no amplo aparato institucional que fundamenta a existência da civilização humana.

Em um plano abrangente, a matriz institucional, na linha defendida por North, estabelece os incentivos que delimitam as percepções dos indivíduos e suas tomadas de decisão, ou seja, as instituições "basically alter the price individuals pays and hence lead to ideas, ideologies, and dogmas" (North, 1990, p. 22). Numa perspectiva semiótica, a fundamentação cognitiva desse mecanismo refere-se à produção de representações emergentes oriundas da instância coletiva. As instituições, desse modo, são instrumentos normativos que restringem e expandem as possibilidades de operação do sistema econômico, mediante a consolidação de padrões comportamentais que regem a operação dos mercados. Verifica-se, que, sob uma perspectiva ontológica, as organizações apresentam certas propriedades emergentes (Chassagnon, 2014):

i. Congregam recursos humanos e não-humanos com o objetivo de geração de lucros;

ii. As interações sociais são resultado do enforcement proveniente da ação dos contratos;

iii. Dispõem de caráter jurídico próprio estabelecido por normas legais formais;

iv. Desenvolvem uma identidade própria que atua como instrumento de coesão e comprometimento organizacionais.

Numa abordagem microanalítica, a organização constitui-se de "working rules" que operam sob a orientação de "managerial transactions" (Commons, 1931, p. 650). Essas transações delimitam a aquisição e alienação de direitos e obrigações no âmbito da organização, no que Commons (1931, p. 648) define por "collective action in control, liberation and expansion of individual action".

Por outro lado, o intrínseco caráter estocástico da realidade induz à busca por ordem e estabilidade. De acordo com Peirce (CP 1.390), o estabelecimento de hábitos e rotinas é um processo natural da mente com vistas a expandir sua capacidade instrumental frente a experiências prevalentes. Concomitantemente, esse mecanismo amplia as potencialidades cognitivas individuais frente a fenômenos desconhecidos. Por seu turno, os comportamentos habituais são medidos por sua eficácia instrumental (CP 5.367). Os hábitos são continuamente avaliados pela inferência de seus resultados e, sob o âmbito social, possuem a propriedade de tornarem-se padrões comportamentais que moldam a interação coletiva.

Sob uma perspectiva das estratégicas corporativas, a adoção de modos de governança, mediante o processo semiótico, é o caminho para o surgimento dos "framings" comportamentais. Por exemplo, Grandori e Furnari (2008) qualificam as estruturas de governança interna como elementos organizacionais que incluem uma coleção de práticas e rotinas. Os elementos de mercado contêm incentivos monetários e de controle. Os elementos burocráticos incluem regras e planos formais de divisão do trabalho, e os elementos comunitários incorporam compartilhamento de decisões, como o compartilhamento de conhecimento, valores e cultura. Cada um desses elementos está relacionado a mecanismos de incentivos, pois atuam criando estímulos para acionar um "goal frame" distinto. No caso da coordenação via mercado, trata-se de uma estrutura que permite estimular incentivos de ganhos. No caso dos elementos burocráticos, atua de forma a inibir que 0 comportamento hedônico se sobressaia, mediante meios de controle/monitoramento dos indivíduos. Por fim, os elementos comunitários atuam através da identidade comum e coesão entre indivíduos, que se orientam a partir de padrões normativos. 
Conforme exposto, o caráter desses intercâmbios relacionais, entretanto, depende das representações semióticas gestadas coletivamente que se traduzem em tendências comportamentais. Há um fluxo contínuo de produções de novas semioses (sinequismo) e, consequentemente, de novas representações (interpretantes) que se moldam ao caráter estocástico das transformações ambientais (tiquismo). A constituição de novos hábitos e rotinas, que se traduzem em modos de governança, é produto dessas concepções. Conforme Peirce defende, as formulações semióticas são aplicadas à normatividade das relações sociais. Nesse sentido, possuem um caráter dinâmico voltado à ação e à mudança de padrões de decisão (Dentz, 2010). Prescreve-se, dessa maneira, que a delimitação do processo de decisão organizacional, sob uma perspectiva semiótica, determina implicações analíticas para a emergência de representações coletivas. As estratégias corporativas ao visarem ampliar o grau de coesão social enfrentam o desafio de identificarem os fatores constitutivos da emergência das concepções coletivas em meio à diversidade. Como resultante, a contribuição da semiótica de Peirce evidencia as potencialidades e a relevância deste escopo analítico voltado ao entendimento das influências das propriedades simbólicas ao processo de decisão e, dessa forma, para a estratégia organizacional.

\section{Conclusão}

O campo de estudos organizacionais defronta-se com o desafio do desenvolvimento de uma nova microfundamentação dos princípios da tomada de decisão individual. A complexidade desse empreendimento resulta do fato do processo decisório ser resultante das influências concomitantes das dimensões relacionais, ambientais e comportamentais. Adicionalmente, essas interações são realizadas em diversos níveis, partindo de estruturas normativas mais gerais - macro - que organizam e moldam as relações interpessoais, em nível micro. Portanto, a busca do estabelecimento de fundamentações comportamentais não deve edificar-se numa relação de causalidade unívoca, baseada tão somente no individualismo metodológico ou nas influências ambientais. Pelo contrário, uma visão holística de cunho realista deve incorporar as influências concomitantes da influência ambiental, da matriz institucional e das estruturas de governança para a emergência de "framings" comportamentais.

Neste cenário analítico, as contribuições do filósofo Charles Sanders Peirce, fundadas em sua abordagem semiótica, são capazes de elucidar os princípios constitutivos da emergência das lógicas de decisão individuais. Sob uma construção ontológica, as bases fenomenológicas de suas categorias existenciais oferecem os mecanismos da operação do processo semiótico que gesta a produção de representações. Destacam-se os seus aspectos emergente e constitutivo que relacionam, de forma abrangente, a ação do ambiente externo (objetos), os instrumentos de representação (signos) e as produções cognitivas gestadas pelos indivíduos (interpretantes). A lógica de decisão, nessa concepção, é produto da ação conjunta dessas três dimensões. Verifica-se o caráter irredutível desse modelo analítico que incorpora conjuntamente os aspectos ambientais e normativos (simbólicos) em seu escopo epistemológico. Sob esse enfoque, o modelo semiótico de decisão proposto no presente ensaio, apesar de simplificado, identifica nas organizações a relação imanente existente entre a dimensão normativa (institucional), o ambiente competitivo (mercado) e os modos de governança. Ao se transporem para a realidade organizacional, os princípios da ontologia social, verifica-se que a dimensão institucional apresenta caráter constitutivo e simbólico, entendida como o conjunto de signos socialmente aceitos. Por outro lado, a ação do ambiente competitivo exerce o papel de força adaptativa e de seleção e, assim, de desenvolvimento de padrões comportamentais (hábitos e rotinas).

Evidencia-se, portanto, que a síntese da tríade peirceana compreende a elaboração de semioses coletivas que atuam sobre as representações individuais. Na perspectiva das microfundamentações, os "framings" comportamentais desenvolvem-se determinando a emergência de padrões comportamentais. Nesse aspecto, ressalta-se a relevância dos estágios relacionais que se identificam com a edificação de objetivos comuns, dessa forma de cunho normativo. Relevantemente para os propósitos da estratégica organizacional, o modelo semiótico indica que, inversamente, a autonomia individual também exerce poder de influência para a gestação 
das representações. Ou seja, a relação "botton-up", na linha do individualismo metodológico, possui respaldo na posição de Peirce quanto à reatividade humana direcionada à transformação de comportamentos habituais.

Por fim, cabe destacar que, na conjuntura econômica atual, caracterizada pela importância da geração e compartilhamento de novos conhecimentos, além da crescente diversidade cultural no meio organizacional, sinaliza-se a relevância do desempenho organizacional da emergência de percepções compartilhadas. A coesão social, nesse aspecto, constitui-se em um atributo coletivo alcançado mediante a edificação de representações de cunho simbólico que são respaldadas coletivamente. A estratégia corporativa defronta-se com o desafio do entendimento dos processos semióticos formadores da densidade dessas relações, especialmente, no âmbito da literatura nacional. Por conseguinte, o presente ensaio sinaliza e circunscreve os meios pelos quais as interações semióticas atuam como instrumentos formadores dos "framings" comportamentais e, portanto, os fundamentos da estratégia corporativa.

\section{Referências}

Abell, P., Felin, T., \& Foss, N. (2008). Building micro-foundations for the routines, capabilities, and performance links. Managerial and decision economics, 29(6), 489-502.

Bacon, M. (2012). Pragmatism: an introduction. Cambridge: Polity Press, $221 \mathrm{p}$.

Barney, J. B. (1986a). Organizational culture: Can it be a source of sustained competitive advantage? Academy of Management Review, 11(3), 656-665.

Barney, J. B. (1986b). Strategic factor markets: Expectations, luck, and business strategy. Management science, 32(10), 1231-1241.

Barney, J. B. (1991). Firm resources and sustained competitive advantage. Journal of Management, 17, 99-120.

Barney, J.B. (1991). Gaining and sustaining competitive advantage. Journal of Management, 17(1), 99-120.

Barney, J. B. (2002). Gaining and sustaining competitive advantage (2nd. ed.) Prentice Hall.

Brier, S. (2008). The paradigm of peircean biosemiotics. Signs-International Journal of Semiotics, 2, 30-81.

Carvalho, C. E., Bandeira-de-Mello, R., Gonçalves Vianna, S. L., \& Marcon, R. (2009). Performance heterogeneity in Latin America: An investigation into the transient effects of country of origin. Latin American Business Review, 10(4), 289-308.

Chassagnon, V. (2014). Toward a social ontology of the firm: reconstitution, organizing entity, institution, social emergence and power. Journal of Business Ethics, 124(2), 197-208.

Colapietro, V. M. (2015). Peirce e a abordagem do self. São Paulo: Intermeios.

Commons, J. R. (1931). Institutional economics. American Economic Review, 21, 648-657.

Demsetz, H. (1988). The theory of the firm revisited. Journal of Law, Economics, \& Organization, 4(1), 141 161.

Dentz, R. A. (2010). Percepção e generalidade em Charles Peirce. Cognitio-Estudos: Revista Eletrônica de Filosofia, 7(1), 19-25.

Dierickx, I., \& Cool, K. (1989). Asset stock accumulation and sustainability of competitive advantage. Management science, 35(12), 1504-1511.

Felin, T., Foss, N. J., \& Ployhart, R. E. (2015). The microfoundations movement in strategy and organization theory. The Academy of Management Annals, 9(1), 575-632. 
Foss, N. J. (2016). Reflections on a decade of micro-foundations research. Revista de Administração, 51(1), 117-120.

Foss, N. J. (2011). Invited editorial: Why micro-foundations for resource-based theory are needed and what they may look like. Journal of Management, 37(5), 1413-1428.

Foss, N. J. (2010). Micro-foundations for management research: What, why, and whither? Cuadernos de Economía y Dirección de la Empresa, 13(42), 11-34.

Foss, N. J. (2004). Cognition and motivation in the theory of the firm: interaction or "never the twain shall meet"? Journal des Économistes et des Études Humaines, 14(1).

Foss, N. J., \& Lindenberg, S. (2013). Microfoundations for strategy: A goal-framing perspective on the drivers of value creation. Academy of Management Perspectives, 27(2), 85-102.

Goldszmidt, R. G. B., Brito, L. A. L., \& de Vasconcelos, F. C. (2011). Country effect on firm performance: A multilevel approach. Journal of Business Research, 64(3), 273-279.

Grandori, A., \& Furnari, S. (2008). A chemistry of organization: Combinatory analysis and design. Organization Studies, 29(3), 459-485.

Helfat, C. E., \& Peteraf, M. A. (2015). Managerial cognitive capabilities and the micro-foundations of dynamic capabilities. Strategic Management Journal, 36(6), 831-850.

Hodgson, G. M. (2019). Prospects for institutional research. RAUSP Management Journal, 54(1), 112-120.

Hodgson, G. M. (2006). What are institutions? Journal of Economic Issues, XL(1), 1-26.

Hodgson, G. M. (2007). The revival of Veblenian institutional economics. Journal of economic issues, 41(2), 324-340.

Ibri, I. A. (2015). Kósmos Noetós: A arquitetura metafísica de Charles S. Peirce. São Paulo: Paulus.

Lawson, T. (1996). Developments in economics as realist social theory. Review of Social Economy, LIV(4), 405-423.

Lawson, T. (2003). Reorienting Economics. London and New York: Routledge.

Lawson, T. (2012). Ontology and the study of social reality: Emergence, organization, community, power, social relations, corporations, artefacts and money. Cambridge Journal of Economics, 36, 345-385.

Lawson, T. (2015). The nature of the firm and peculiarities of the corporation. Cambridge Journal of Economics, 39, 1-32.

Lindenberg, S. (2001). Intrinsic motivation in a new light. Kyklos, 54(2-3), 317-342.

Lindenberg, S., \& Steg, L. (2007). Normative, gain and hedonic goal frames guiding environmental behavior. Journal of Social Issues, 63(1), 117-137.

Lippman, S. A., \& Rumelt, R. P. (1982). Uncertain imitability: An analysis of interfirm differences in efficiency under competition. The Bell Journal of Economics, 13(2), 418-438.

Malerba, F., \& Orsenigo, L. (2000). Knowledge, innovative activities and industrial evolution. Industrial and corporate change, 9(2), 289-314.

McCloskey, D. N. (2016). Max U versus Humanomics: A critique of neo-institutionalism. Journal of Institutional Economics, 12(1), 1-27.

McGahan, A. M., \& Porter, M. E. (1997). How much does industry matter, really? Strategic Management Journal, 18(S1), 15-30. 
Molina-Azorín, J. F. (2014). Micro-foundations of strategic management: Toward micro-macro research in the resource-based theory. BRQ Business Research Quarterly, 17(2), 102-114.

Nellhaus, T. (1998). Signs, social ontology, and critical realism. Journal for the Theory of Social Behaviour, 28(1), 1-24.

Nelson, R. R., \& Winter, S. G. (1982). An evolutionary theory of economic change. Cambridge, Mass: Belknap Press.

North, D. C. (1990). Institutions, institutional change, and economic performance. Cambridge, Mass: Cambridge University Press.

Peirce, C. S. ([1866-1913] 1931-1958). Collected Papers of Charles Sanders Peirce (Vols. 1-6, 19311935). C. Hartshorne, \& P. Weiss, (Eds.). Cambridge, Mass: Harvard University Press (electronic edition).

Peirce, C. S. ([1866-1913] 1931-1958). Collected Papers of Charles Sanders Peirce (Vols. 7-8, 1958). A. W. Burks (Ed.). Cambridge, Mass: Harvard University Press (electronic edition).

Peteraf, M. A. (1993). The cornerstones of competitive advantage: A resource-based view. Strategic Management Journal, 14(3), 179-191.

Phipps, C. (2014). Evolucionários. São Paulo: Cultrix.

Porter, M. E. (1985). The competitive advantage: Creating and sustaining superior performance. NY: Free Press.

Prahalad, C. K., \& Hamel, G. (1990). The core competence and the corporation. Harvard Business Review, 68(3), 79-91.

Rosenthal, S. B. (1990). Speculative pragmatism. Chicago: Open Court Pub. Co.

Rumelt, R. P. (1991). How much does industry matter? Strategic Management Journal, 12(3), 167-185.

Santaella, L. (2002). Semiótica aplicada. São Paulo: Pioneira Thomson Learning.

Santaella, L. (2004). Contribuições do pragmatismo de Peirce para o avanço do conhecimento. Revista de Filosofia, 16(18), 75-86.

Schmalensee, R. (1985). Do markets differ much? The American Economic Review, 75(3), 341-351.

Searle, J. R. (1984). Minds, brains, and science. Cambridge, Mass: Harvard University Press.

Searle, J. R. (2005). What is an institution? Journal of Institutional Economics, 1(1), 1-22.

Teece, D. J., Pisano, G., \& Shuen, A. (1997). Dynamic capabilities and strategic management. Strategic Management Journal, 18(7), 509-533.

Tuomela, R. (2003). Collective acceptance, social institutions, and social reality. American Journal of Economics and Sociology, 62(1), 123-165.

Wernerfelt, B. (1984). A resource-based view of the firm. Strategic Management Journal, 5(2), 171-180.

World Bank Group (2015). World development report 2015: Mind, society, and behavior. Washington, DC: World Bank. 


\section{Sobre os Autores}

\section{Luís Otávio Bau Macedo}

Professor do Programa de Pós-Graduação em Gestão e Tecnologia Ambiental da Universidade Federal de Mato Grosso. Doutor em Economia Aplicada pela Escola Superior de Agricultura Luiz de Queiroz da Universidade de São Paulo. Email: luis_otavio@ufmt.br. ORCID: 0000-0002-2002-5366

\section{Maria Sylvia Macchione Saes}

Professora do Programa de Pós-Graduação em Administração da Faculdade de Economia, Administração e Contabilidade da Universidade de São Paulo. Doutora em Administração pela Universidade de São Paulo. Email: ssaes@usp.br. ORCID: 0000-0002-6344-0113 